\title{
Examining Individual Differences in Social Reward Valuation: a Person-Based Approach
}

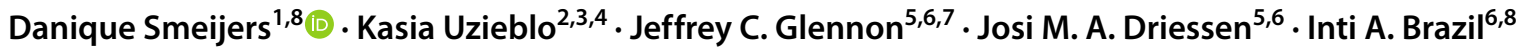

Accepted: 29 September 2021 / Published online: 19 October 2021

(c) The Author(s) 2021

\begin{abstract}
Social reward refers to the motivational and pleasurable aspects of our interactions with other people. While some people experience social encounters as pleasurable, others experience them as aversive. However, the current knowledge on individual differences in social reward valuation in relation to pro- and antisocial personality characteristics is limited. The Social Reward Questionnaire (SRQ) was developed to assess individual differences in the value of different types of social rewards. First, the present study examined the validity and reliability of the Dutch version of the SRQ in a Dutch and Flemish community sample $(N=1892)$. Second, using latent profile analysis (LPA), it was investigated whether subgroups of participants existed with distinctive patterns of social reward valuation, and whether these subgroups differed in their level of psychopathic traits, aggression, and social anxiety. The results confirmed the original six-factor structure and showed good reliability and validity. The LPA identified four classes of individuals, labelled as: Low Social Interest, High Social Interest, Undifferentiated Social Reward-seekers, and Socially Cruel. These classes were further typified by distinct levels of psychopathy, reactive and proactive aggression, and social anxiety. The present findings contribute to our understanding of individual variability in the underlying motives of social behaviors.
\end{abstract}

Keywords Social reward value $\cdot$ Individual differences $\cdot$ Psychopathy $\cdot$ Person-based approach

In daily life, we often engage in behaviors that lead to pleasurable and rewarding outcomes. Experimental research has shown that the prospect of obtaining rewards plays a key role in shaping our behaviors, as this prospect is believed

Danique Smeijers

danique.smeijers@ru.nl; daniquesmeijers@gmail.com

1 Behavioural Science Institute, Radboud University, 6500 HC Nijmegen, The Netherlands

2 Ghent University, Ghent, Belgium

3 De Forensische Zorgspecialisten, Utrecht, The Netherlands

4 Vrije Universiteit Brussel, Brussels, Belgium

5 Radboud University Medical Centre, Cognitive Neuroscience, Nijmegen, The Netherlands

6 Donders Institute for Brain, Cognition and Behaviour, Radboud University, Nijmegen, The Netherlands

7 School of Medicine, Conway Institute of Biomolecular and Biomedical Research, University College Dublin, Dublin, Ireland

8 Forensic Psychiatric Centre Pompestichting, Nijmegen, The Netherlands to guide the selection of actions that help us maximize the chance of attaining rewarding outcomes (Bhanji \& Delgado, 2014). Importantly, a lot of our behaviors occur in social contexts, and social interactions are thought to be particularly rewarding. Social reward is defined as the motivational and pleasurable aspects of our interactions with other people (Foulkes et al., 2014a).

To differentiate among types of social rewards and to assess individuals differences in the valuation of such rewards in adults, Foulkes et al. (2014b) developed the Social Reward Questionnaire (SRQ). The SRQ consists of 23 items, subdivided in six subscales: 1) Admiration, the enjoyment of being flattered and gaining positive attention; 2) Negative Social Potency, the enjoyment of being cruel, antagonistic, and using others; 3) Passivity, the enjoyment of giving others control and allowing them to make decisions; 4) Prosocial Relationships, the enjoyment of having kind and reciprocal relationships; 5) Sexual Relationships, the enjoyment of frequent sexual intimacy; and 6) Sociability, the enjoyment of engaging in group interactions. All items are rated on a 7 -point scale $(1=$ strongly disagree, $7=$ strongly agree). The SRQ was investigated in an international (MTurk) sample, 
consisting of proficient English readers, and showed to have adequate levels of internal consistency (Cronbach a ranging from 0.77 to 0.87 ), good test-retest reliability at an interval of 2 weeks ( $r$ ranging from 0.69 to 0.88 ), and good construct validity. Social reward valuation was also found to be associated with the big five personality traits: Admiration was positively correlated with extraversion and openness; Negative Social Potency was negatively associated with agreeableness, conscientiousness, and emotionality, and positively with openness to experience; Passivity was negatively associated with conscientiousness, emotionality, and openness to experience; Prosocial Relationships was positively correlated with all big five personality traits; Sexual Relationships was positively associated with extraversion and openness to experience; and Sociability correlated positively with agreeableness, emotionality, extraversion, and openness to experience.

Prior research with the SRQ indicates that age and culture may be demographic factors that could affect social reward valuation. Foulkes et al. (2017) developed an adapted version of the SRQ for adolescents. The main difference with the original version was the removal of the sexual relationships subscale. The factor structure of the SRQ based on the five left subscales remained unchanged in an adolescent sample, and similar patterns of associations were found with the big five personality traits. This implies that the factor structure of the SRQ is relatively robust across different age groups, although the groups may differ in their social activities. In another study, the SRQ was translated to Persian and showed acceptable to good reliability (Arab Mohebi Shahrabi et al., 2017). However, the original six-factor structure was not confirmed. A four-factor solution was found instead in which the original items were re-clustered in the following subscales: acceptance, prosocial interactions, sexual/abusive relations, and negative social potency. These results highlight that cultural differences may exist in what is considered to be rewarding during social interactions. Therefore, it is important to further elucidate similarities or differences in the robustness of social reward types and individual differences in the valuation of such rewards across cultures and populations. Also, because the SRQ's original validation was investigated in a sample of individuals with mixed cultural backgrounds (e.g., African-American, Hispanic, Asian), it may mask unique cultural structures.

Regarding types of social rewards, it is thought that interpersonal kindness and closeness form a fundamental facet of social reward for most people. However, some individuals experience social behaviors such as being callous, cruel, and using others for personal gains to be highly rewarding (Buss, 1983; Foa \& Foa, 1980). It seems that such individual differences are associated with specific forms of psychopathology. For instance, a condition associated with an atypical experience of social reward is psychopathy. Psychopathy is characterized by callousness, shallow affect, impulsivity, and antisocial behavior. The current dominant belief is that psychopathic traits vary along four dimensions, capturing interpersonal and affective disturbances, antisocial tendencies and an inclination towards leading an erratic lifestyle (Hare, 2003). Individuals with higher levels of psychopathic traits or its early developmental counterpart, callous-unemotional traits, seem to enjoy callous and antisocial behavior more than prosocial behaviors (Foulkes et al., 2014a, b, 2017). It was suggested that individuals high in psychopathic traits not only fail to empathize with others' distress, but also derive pleasure from engaging in cruel behavior. Additionally, Foulkes et al. (2014a) found that the affective, interpersonal, and lifestyle components of psychopathy were positively associated with the enjoyment of sexual intimacy. Interpersonal psychopathic traits were also found to be positively associated with the enjoyment of being flattered and gaining positive attention (i.e., admiration), even over monetary rewards. The interpersonal factor of psychopathy is characterized by manipulativeness, grandiose self-worth, and superficial charm (Hare \& Neumann, 2008). It was suggested that admiration may fuel these narcissistic traits and is, therefore, valued as rewarding (Foulkes et al., 2014a). These findings enhance our understanding of the possible motives behind social behaviors in individuals with elevated levels of psychopathy.

While obtaining social rewards may partly motivate behaviors that are disruptive to others in individuals with psychopathic tendencies (Foulkes et al., 2014a, b, 2017), social rewards seem to lack sufficient motivational power in individuals with higher levels of social anxiety (Cremers et al., 2015). Socially anxious individuals actively try to avoid social encounters that may lead to feeling judged or rejected by others (APA, 2013). When actively avoiding social interactions is not possible, highly socially anxious individuals tend to display withdrawal-related behavior during interactions, such as avoiding eye contact (for a review see Chen \& Clarke, 2017). The behaviors seen in individuals with high social anxiety indicate that such individuals may present with disturbances in the motivation to have healthy and rewarding social interactions. Such a disturbance could be (partly) driven by a fundamental impairment in processing the value of rewarding events. Indeed, neuroscientific research has shown that individuals with high social anxiety exhibit a dysfunction in reward processing in a task in which facial expressions were used as reinforcers (Cremers et al., 2015). There is also neuroscientific evidence that psychopathic individuals show an increased reward sensitivity (for a review see Ling \& Raine, 2018). Additionally, reduced social reward conditioning has been found to be associated with proactive (i.e., instrumental) but not with reactive (i.e., impulsive) aggression in children (Gao et al., 
2018). Thus, both psychopathy, proactive aggression, and social anxiety seem to be associated with impairments in reward processing, even though the impairment is associated with different behavioral tendencies. Importantly, it is unknown how exactly these impairments in reward processing are reflected by behaviors and events that people find socially rewarding in their daily lives. An enhanced understanding of individual differences in the assignment of value to social events could contribute to our understanding of what motivates deviant social behaviors.

The aims of the present study were three-fold. First, we examined the validity and reliability of the Dutch version of the SRQ. Second, convergent and discriminant validity were examined by investigating the association between the Dutch version the SRQ and psychopathy, aggression subtype, social anxiety, and personality characteristics. In line with the aforementioned literature, it was hypothesized that psychopathy, proactive aggression, and openness to experience were positively associated with Negative Social Potency. A positive association was expected between Admiration and psychopathy, both aggression subtypes, and extraversion. Passivity was hypothesized to be positively associated with social anxiety (Chen \& Clarke, 2017; Cremers et al., 2015), and negatively with conscientiousness, emotionality, and openness to experience. A negative association was expected between Prosocial Relationships and psychopathy and social anxiety (Chen $\&$ Clarke, 2017; Cremers et al., 2015), and a positive association was expected with all big five personality traits. The scale Sexual Relationships was hypothesized to be positively associated with psychopathy, proactive aggression, extraversion and openness to experience, and negatively with social anxiety. Sociability was expected to be positively associated with psychopathy, both aggression subtypes, agreeableness, emotionality, extraversion, and openness to experience, and negatively with social anxiety. All hypotheses about the association between the SRQ scales and psychopathy, aggressive behavior, and personality constructs were in line with the studies by Foulkes et al. (2014a, b, 2017). Third, a person-based approach (latent profile analysis) was used to assess whether subgroups of participants existed with a distinctive social reward value pattern and whether these subgroups differed in their level of psychopathy, aggression, and social anxiety. Based on the aforementioned hypotheses, it was expected that the person-based approach would find subgroups of individuals that were mainly characterized by high scores on either 1) admiration, prosocial relationships, sexual relationships, and sociability (i.e., high social reward valuation and displaying social behavior); or 2) passivity (i.e., more socially withdrawn); or 3 ) on negative social potency (socially inverted).

\section{Methods}

\section{Participants}

The current study consisted of a Dutch and Belgian sample. In total, 1892 participants $(74.8 \%$ female and $25.2 \%$ male) were included. The Dutch Sample consisted of 1543 participants $(78.7 \%$ female and $21.3 \%$ male), with a mean age of 21.11 years $(S D=6.13)$. The majority were undergraduate students from the Radboud University Nijmegen, The Netherlands $(N=1307 ; 84.7 \%) . \mathrm{N}=236$ were recruited from the general population. The Flemish sample consisted of 349 participants $(57.3 \%$ female and $42.7 \%$ male) and had a mean age of 20.49 years $(S D=7.21)$. This sample was recruited from the general population; about one third (32\%) were bachelor students from the Thomas More University College, Belgium. It is important to note that the native language of the Belgian participants was Flemish, which is a variant of the Dutch language. The variants of Dutch spoken in Belgium and in the Netherlands have the same grammatical and semantic characteristics, but the pronunciation of some words can differ. Flemish and Dutch are the same language, but with different regional accents. Both countries are very similar in many other aspects as well, including most population demographics, which is unsurprising given that they used to form one country. Therefore, both samples were combined in the current study.

\section{Materials}

The Social Reward Questionnaire (SRQ) is a self-report measure of individual differences in the value of social rewards. The SRQ consists of 23 statements that are divided into six subscales: Admiration, negative social potency, passivity, prosocial interactions, sexual relationships, and sociability. Participants receive the instruction to consider how well each statement relates to them and to rate the extent to which they agree with these statements on a 5 -point Likert scale ( $1=$ disagree strongly, $5=$ agree strongly). The Dutch version of the SRQ was created in the current study (see Procedure). The SRQ was administered in both the Dutch and Flemish sample.

The Self-Report Psychopathy Short-Form (SRP-SF; Paulhus et al., 2010, 2015) is a self-report measure of psychopathic features. The SRP-SF consists of 29 statements that are divided into four subscales: Interpersonal manipulation, callous affect, erratic life styles, and criminal tendencies. Participants have to rate the extent to which they agree with these statements on a 5-point Likert scale $(1=$ disagree strongly, $5=$ agree strongly). Prior research indicates that the Dutch version of the SRP-SF 
has questionable to acceptable internal-consistency and test-retest reliability (Cronbach's a ranging from 0.58 to 0.73 and $r$ ranging from 0.60 to 0.86 ; (Gordts et al., 2015)). In the current study, the internal consistency ranged from questionable to good (Cronbach's a ranging from 0.52 to 0.90; mean inter-item correlations (MIC) ranging from $0.274-0.392$ ). The SRP-SF was only administered in the Dutch sample.

The Reactive Proactive Questionnaire (RPQ; Cima et al., 2013; Raine et al., 2006) is a 23-item self-report questionnaire to measure reactive and proactive aggression. The reactive subscale consists of 11 items, whereas the proactive subscale consists of 12 items. The items are rated 0 (never), 1 (sometimes) or 2 (often). Prior research indicates that the Dutch translation has good internal consistency (Cronbach's Alpha $=0.91)$ and adequate convergent (all $r>0.16$ ), criterion and construct validity (Cima et al., 2013). In the current study, the internal consistency was good (Cronbach's $a=0.81$ for reactive aggression; 0.83 for proactive; $\mathrm{MIC}=0.278$ for reactive; 0.330 for proactive). The RPQ was only administered in the Dutch sample.

The Liebowitz Social Anxiety Scale (LSAS) is a 24-item self-report questionnaire to assess social anxiety and avoidance (Liebowitz, 1987; Van Balkom et al., 2004). Each item is rated for level of fear (ranging from $0=$ none to $3=$ severe) and avoidance (ranging from $0=$ none to $3=$ almost always) it triggered in the past week. Both the original and the Dutch version have proven psychometric properties. In the current study the internal consistency was excellent (Cronbach's a anxiety $=0.94$ for avoidance: 0.92 ; $\mathrm{MIC}=0.386$ for avoidance; 0.327 for anxiety). The LSAS was only administered in the Dutch sample.

The HEXACO-60 (Ashton \& Lee, 2009) is a 60-item self-report questionnaire to measure six personality factors according to the HEXACO model: honesty-humility (e.g., integrity, sincerity, fairness), emotionality (e.g., fearfulness, anxiety, dependence), extraversion (e.g., social self-esteem, social boldness, sociability), agreeableness versus anger (e.g., forgiveness, gentleness, patience), conscientiousness (e.g., organization, diligence, patience), and openness to experience (e.g., aesthetic appreciation, inquisitiveness, creativity). Participants have to rate the extent to which they agree with these statements on a 5-point Likert scale $(1=$ strongly disagree, $5=$ strongly agree). Both the original and the Dutch version had acceptable to good internal-consistency (Cronbach's a ranging from 0.73 to 0.80 and from 0.88 to 0.92 , respectively) (Ashton \& Lee, 2009; De Vries et al., 2009). In the present study, the internal consistency ranged from questionable to good (Cronbach's a ranging from 0.59 to 0.79 ; MIC ranging from $0.116-0.482$ ). The HEXACO-60 was only administered in the Dutch sample.

\section{Procedure}

The Dutch version of the SRQ was created using a backtranslation procedure. First, the original SRQ was translated to Dutch independently by two individuals under supervision of KU. Then, the first Dutch version was translated back to English by IAB, and the final Dutch version was determined based on consensus between KU and IAB.

The questionnaires were administered online and were completed individually, with all the required information and instructions provided in writing. Participants signed a consent form after receiving information about the nature of the study. Undergraduate students received course credits for their participation when applicable (both sites), while the participants from the general population were entered in a lottery to win movie tickets or a financial reward.

\section{Statistical Analyses}

First, the means, standard deviations, skewness and kurtosis statistics for the SRQ total and the individual subscale scores were calculated. Next, the internal reliability of the SRQ Dutch version in the current sample was investigated using Cronbach's $a$ and mean inter-item correlations. The following cutoffs of Cronbach's Alpha are used: $\geq 0.9=$ excellent,$\geq 0.8=$ good,$\geq 0.7=$ acceptable,$\geq 0.6=$ questionable, $\geq 0.5=$ poor, and $\leq 0.5=$ unacceptable (Gliem \& Gliem, 2003). The mean inter-item correlation for a set of items should be between 0.20 and 0.40 (Piedmont, 2014). Subsequently, a confirmatory factor analysis (CFA) was used to verify the six-factor model of the SRQ (Foulkes et al., 2014b). The analysis was conducted with a WLSMV estimator in Mplus version 7 (Muthén \& Muthén, 1998). The SRQ items were rated on a 5-point Likert scale, thus yielding ordinal data. Therefore, the WLSMV estimator was favored because it is specifically designed for categorical (e.g., binary or ordinal) observed data (e.g., (Li, 2016) and is the same estimator used by Foulkes et al. (2014b). Model fit was evaluated using absolute and conventional fit indices; the Chi-square statistic, the Comparative Fit Index (CFI), the Tucker-Lewis Index (TLI), and the Root Mean Square Error of Approximation (RMSEA). Model fit was considered to be good for CFI and TLI values greater than 0.90, a RMSEA of 0.06 or lower, and a non-significant Chi-square test $(p>0.05)$ (Hooper et al., 2008; Hoyle, 1995; Hu \& Bentler, 1999). A factor loading $\geq 0.4$ was considered strong (Field, 2013).

Third, the convergent and discriminant validity were examined only in the Dutch sample using correlation analysis. A bootstrapping procedure (5000 iterations) was used to determine $95 \%$ confidence intervals and to test the significance of the correlations. By bootstrapping, one is able to simulate the population distribution of the correlation and to 
Table 1 Descriptive characteristics for the Dutch SRQ

\begin{tabular}{llllcccc}
\hline Questionnaire & $\boldsymbol{\alpha}$ & $\boldsymbol{r}$ & $\boldsymbol{M}(\boldsymbol{S D})$ & Skewness & SE & Kurtosis & SE \\
\hline SRQ Admiration & .794 & .488 & $5.33(1.10)$ & -.812 & .056 & .804 & .112 \\
SRQ Negative Social Potency & .715 & .397 & $1.74(.84)$ & 1.855 & .056 & 4.950 & .112 \\
SRQ Passivity & .764 & .518 & $2.99(1.19)$ & .2973 & .056 & -.377 & .112 \\
SRQ Prosocial Interactions & .708 & .341 & 6.16 & -1.881 & .056 & 6.182 & .112 \\
SRQ Sexual Relationships & .766 & .435 & $4.53(1.54)$ & -.448 & .056 & -.389 & .112 \\
SRQ Sociability & .652 & .386 & $5.34(1.16)$ & -1.033 & .056 & 1.119 & .112 \\
SRP Interpersonal & .812 & .392 & $11.55(4.46)$ & 1.208 & .062 & 1.299 & .125 \\
SRP Affective & .721 & .313 & $9.23(3.39)$ & 1.573 & .062 & .876 & .125 \\
SRP Erratic lifestyle & .781 & .348 & $12.93(4.47)$ & .977 & .062 & .876 & .125 \\
SRP Antisocial & .523 & .350 & $6.99(2.52)$ & 4.192 & .062 & 24.364 & .125 \\
SRP Total & .901 & .274 & $43.03(12.94)$ & 1.755 & .062 & 4.701 & .125 \\
LSAS Anxiety & .937 & .386 & $41.59(14.96)$ & 1.030 & .062 & .543 & .125 \\
LSAS Avoidance & .919 & .327 & $35.54(12.95)$ & 1.271 & .065 & 2.362 & .129 \\
RPQ Proactive & .827 & .330 & $13.14(0.6)$ & 3.674 & .062 & 19.09 & .125 \\
RPQ Reactive & .807 & .278 & $16.39(3.57)$ & .687 & .062 & .383 & .125 \\
HEXACO HH & .586 & .116 & $3.89(.53)$ & -.269 & .065 & .029 & .130 \\
HEXACO Emotion & .772 & .254 & 3.34 & -.388 & .065 & .035 & .130 \\
HEXACO Extraversion & .790 & .276 & $3.42(.61)$ & -.460 & .065 & .261 & .130 \\
HEXACO Agreeableness & .706 & .195 & $3.22(.57)$ & -.195 & .065 & .090 & .130 \\
HEXACO conscientiousness & .796 & .278 & $3.58(.64)$ & -.251 & .065 & -.237 & .130 \\
HEXACO Openness to experience & .751 & .229 & $3.14(.69)$ & -.041 & .065 & -.357 & .130 \\
\hline
\end{tabular}

$r=$ mean inter-item correlations provide confidence intervals for the correlation coefficients (Sideridis \& Simos, 2010). Moreover, this approach yields more accurate estimates compared to estimates obtained without resampling, as would be the case in traditional parametric correlation analysis (Hesterberg et al., 2003).

Finally, a latent profile analysis (LPA) was conducted to identify homogeneous classes of subjects with similar profiles of social reward values in the observed data. The analysis was conducted in Mplus version 7 (Muthén \& Muthén, 1998). The six subscales of the SRQ were used as observed variables for the LPA model. Age was included as covariate to control for the possible influence of age on social reward valuation. The optimal number of classes was determined based upon the Bayesian Information Criteria (BIC; lowest), Entropy ( $>0.70$ ), the Lo-Medel-Rubin (LMR), and the total participants in each class should be higher than the used parameters in the model (Nylund et al., 2007). The LMR test compares the improvement in fit between $k-1$ classes and the $k$ class model. The provided $p$-value indicates whether there is a statistically significant improvement in fit. Subsequently, repeated-measures ANOVA was used to assess differences between social reward values across different classes. Finally, a MANOVA was conducted to investigate whether the classes scored differently on psychopathy, aggression subtype, social anxiety and avoidance, and the HEXACO personality characteristics. The latter analysis was conducted in the Dutch sample only. Age and gender were included as covariates to control for their effects in both the repeated-measures ANOVA and the MANOVA.

\section{Results}

\section{Descriptive Statistics, Internal Consistency, and Convergent and Discriminant Validity}

Descriptive statistics are displayed in Table 1. The internal consistency and mean inter-item correlations were found to vary from good to excellent for all subscales. Finally, the subscale Negative Social Potency correlated negatively with the subscales Prosocial Interactions and Sociability. No significant correlations were found between Negative Social Potency and Admiration and between Passivity and the subscales Prosocial interactions and Sexual relationships. All other subscale scores correlated positively with each other (see Table 2). Correlations with criterion measures are displayed in Table 2.

\section{Factor Analysis}

A CFA was conducted to verify the original six-factor solution of the SRQ. The CFA had an acceptable fit: $\chi^{2}$ $(215)=2351.774, p<0.001 ; \mathrm{CFI}=0.91$; TLI $=0.89$; and 
Table 2 Correlations between subscales of the SRQ and the LSAS, SRP, RPQ, and the HEXACO

\section{Admiration Negative social Passivity $\quad$ Prosocial interactions Sexual relationships Sociability} potency

\begin{tabular}{|c|c|c|c|c|c|c|}
\hline \multicolumn{7}{|l|}{ Admiration } \\
\hline \multirow{2}{*}{$\begin{array}{l}\text { Negative social } \\
\text { potency }\end{array}$} & $r=.030$ & - & & & & \\
\hline & $\mathrm{CI}=-.028-.089$ & & & & & \\
\hline \multirow[t]{2}{*}{ Passivity } & $r=.077 * *$ & $r=.147 * *$ & - & & & \\
\hline & $\mathrm{CI}=.029-.129$ & $\mathrm{CI}=.094-.197$ & & & & \\
\hline \multirow{2}{*}{$\begin{array}{l}\text { Prosocial interac- } \\
\text { tions }\end{array}$} & $r=.413 * *$ & $r=-.440 * *$ & $r=-.005$ & - & & \\
\hline & $\mathrm{CI}=.364-.460$ & $\mathrm{CI}=-.500-.374$ & $\mathrm{CI}=-.058-.047$ & & & \\
\hline \multirow[t]{2}{*}{ Sexual relationships } & $r=.353 * *$ & $r=.236^{* *}$ & $r=.039$ & $r=.108 * *$ & - & \\
\hline & $\mathrm{CI}=.310-.397$ & $\mathrm{CI}=.185-.283$ & $\mathrm{CI}=-.013-.087$ & $\mathrm{CI}=.058-.155$ & & \\
\hline \multirow[t]{2}{*}{ Sociability } & $r=.441 * *$ & $r=-.061^{*}$ & $r=.049 *$ & $r=.352 * *$ & $r=.355^{* *}$ & - \\
\hline & $\mathrm{CI}=.398-.482$ & $\mathrm{CI}=-.115-.008$ & $\mathrm{CI}=.000-.098$ & $\mathrm{CI}=.299-.401$ & $\mathrm{CI}=.310-.396$ & \\
\hline SRP Interpersonal & $\begin{array}{l}r=.184 * * *, \\
\mathrm{CI}=.135-.230\end{array}$ & $\begin{array}{l}r=.482 * * * \\
\mathrm{CI}=.423-.543\end{array}$ & $\begin{array}{l}r=.042, \\
\mathrm{CI}=-.012-.096\end{array}$ & $\begin{array}{l}r=-.203 * * *, \\
\mathrm{CI}=-.261--.149\end{array}$ & $\begin{array}{l}r=.287 * * * \\
\mathrm{CI}=.240-.335\end{array}$ & $\begin{array}{l}r=.000, \\
\mathrm{CI}=-.053-.050\end{array}$ \\
\hline SRP Affective & $\begin{array}{l}r=.114 * * * \\
\mathrm{CI}=.058-.165\end{array}$ & $\begin{array}{l}r=.486 * * * \\
\mathrm{CI}=.424-.545\end{array}$ & $\begin{array}{l}r=-.007, \\
\mathrm{CI}=-.061-.047\end{array}$ & $\begin{array}{l}r=-.273 * * * \\
\mathrm{CI}=-.331-.215\end{array}$ & $\begin{array}{l}r=.262 * * * \\
\mathrm{CI}=.208-.312\end{array}$ & $\begin{array}{l}r=-.034, \\
\mathrm{CI}=-.093-.020\end{array}$ \\
\hline SRP Lifestyle & $\begin{array}{l}r=.186^{* * *}, \\
\mathrm{CI}=.130-.234\end{array}$ & $\begin{array}{l}r=.471 * * * \\
\mathrm{CI}=.419-.525\end{array}$ & $\begin{array}{l}r=-.017, \\
\mathrm{CI}=-.069-.036\end{array}$ & $\begin{array}{l}r=-.176^{* * *}, \\
\mathrm{CI}=-.235-.119\end{array}$ & $\begin{array}{l}r=.385^{* * *}, \\
\mathrm{CI}=.335-.431\end{array}$ & $\begin{array}{l}r=.107 * * * \\
\mathrm{CI}=.054-.157\end{array}$ \\
\hline SRP Antisocial & $\begin{array}{l}r=.019 \\
\mathrm{CI}=-.042-.075\end{array}$ & $\begin{array}{l}r=.332 * * * \\
\mathrm{CI}=.255-.424\end{array}$ & $\begin{array}{l}r=.033, \\
\mathrm{CI}=-.026-.090\end{array}$ & $\begin{array}{l}r=-.206^{* * *}, \\
\mathrm{CI}=-.288-.125\end{array}$ & $\begin{array}{l}r=.110^{* * *}, \\
\mathrm{CI}=.054-.167\end{array}$ & $\begin{array}{l}r=-.015 \\
\mathrm{CI}=-.066-.033\end{array}$ \\
\hline SRP Total & $\begin{array}{l}r=.162 * * * \\
\mathrm{CI}=.105-.213\end{array}$ & $\begin{array}{l}r=.541^{* * *}, \\
\mathrm{CI}=.480-.605\end{array}$ & $\begin{array}{l}r=.016, \\
\mathrm{CI}=-.039-.070\end{array}$ & $\begin{array}{l}r=-.254 * * *, \\
\mathrm{CI}=-.319--.194\end{array}$ & $\begin{array}{l}r=.330^{* * *}, \\
\mathrm{CI}=.272-.382\end{array}$ & $\begin{array}{l}r=.024, \\
\mathrm{CI}=-.029-.074\end{array}$ \\
\hline LSAS Anxiety & $\begin{array}{l}r=.000, \\
\mathrm{CI}=-.056-.057\end{array}$ & $\begin{array}{l}r=.106^{* * *}, \\
\mathrm{CI}=.048-.166\end{array}$ & $\begin{array}{l}r=.209 * * * \\
\mathrm{CI}=.155-.261\end{array}$ & $\begin{array}{l}r=-.100 * * *, \\
\mathrm{CI}=-.155--.042\end{array}$ & $\begin{array}{l}r=-.125 * * *, \\
\mathrm{CI}=-.179-.066\end{array}$ & $\begin{array}{l}r=.000, \\
\mathrm{CI}=-.278-.164\end{array}$ \\
\hline LSAS Avoidance & $\begin{array}{l}r=-.030 \\
\mathrm{CI}=-.087-.029\end{array}$ & $\begin{array}{l}r=.125^{* * *}, \\
\mathrm{CI}=.063-.185\end{array}$ & $\begin{array}{l}r=.160 * * * \\
\mathrm{CI}=.103-.213\end{array}$ & $\begin{array}{l}r=-.096 * * *, \\
\mathrm{CI}=-.156-.036\end{array}$ & $\begin{array}{l}r=-.095^{* * *}, \\
\mathrm{CI}=-.151-.038\end{array}$ & $\begin{array}{l}r=.000, \\
\mathrm{CI}=-.300-.182\end{array}$ \\
\hline$R P Q$ Proactive & $\begin{array}{l}r=. .35 \\
\mathrm{CI}=-.029-.219\end{array}$ & $\begin{array}{l}r=.465 * * * \\
\mathrm{CI}=.392-.540\end{array}$ & $\begin{array}{l}r=.042, \\
\mathrm{CI}=-.018-.099\end{array}$ & $\begin{array}{l}r=-.249 * * *, \\
\mathrm{CI}=-.325--.168\end{array}$ & $\begin{array}{l}r=.198 * * * \\
\mathrm{CI}=.151-.243\end{array}$ & $\begin{array}{l}r=-.026, \\
\mathrm{CI}=-.083-.032\end{array}$ \\
\hline$R P Q$ Reactive & $\begin{array}{l}r=.162 * * * \\
\mathrm{CI}=.107-.219\end{array}$ & $\begin{array}{l}r=.275^{* * *}, \\
\mathrm{CI}=.221-.329\end{array}$ & $\begin{array}{l}r=-.058^{*}, \\
\mathrm{CI}=-.111-.003\end{array}$ & $\begin{array}{l}r=-.061 * \\
\mathrm{CI}=-.121-.003\end{array}$ & $\begin{array}{l}r=.211 * * * \\
\mathrm{CI}=.160-.259\end{array}$ & $\begin{array}{l}r=.044 \\
\mathrm{CI}=-.016-.105\end{array}$ \\
\hline НЕХАСО НH & $\begin{array}{l}r=-.188 * * *, \\
\mathrm{CI}=-.243-.128\end{array}$ & $\begin{array}{l}r=-.358 * * *, \\
\mathrm{CI}=-.412--.302\end{array}$ & $\begin{array}{l}r=-.007, \\
\mathrm{CI}=-.065-.049\end{array}$ & $\begin{array}{l}r=.241 * * * \\
\mathrm{CI}=.183-.301\end{array}$ & $\begin{array}{l}r=-.264 * * *, \\
\mathrm{CI}=-.320-.209\end{array}$ & $\begin{array}{l}r=-.062 *, \\
\mathrm{CI}=-.121-.005\end{array}$ \\
\hline HEXACO Emotion & $\begin{array}{l}r=.014, \\
\mathrm{CI}=-.045-.072\end{array}$ & $\begin{array}{l}r=-.238 * * *, \\
\mathrm{CI}=-.289-.186\end{array}$ & $\begin{array}{l}r=.153 * * * \\
\mathrm{CI}=.102-.204\end{array}$ & $\begin{array}{l}r=.254 * * *, \\
\mathrm{CI}=.209-.305\end{array}$ & $\begin{array}{l}r=-.179 * * *, \\
\mathrm{CI}=-.231-.124\end{array}$ & $\begin{array}{l}r=.042, \\
\mathrm{CI}=-.015-.105\end{array}$ \\
\hline \multirow{2}{*}{$\begin{array}{l}\text { HEXACO Extraver- } \\
\quad \text { sion }\end{array}$} & $r=.143 * * *$ & $r=-.064^{*}$ & $r=-.191 * * *$ & $r=.144 * * *$ & $r=.177 * * *$ & $r=.401 * * *$ \\
\hline & $\mathrm{CI}=.087-.198$ & $\mathrm{CI}=-.113--.020$ & $\mathrm{CI}=-.246-.141$ & $\mathrm{CI}=.092-.193$ & $\mathrm{CI}=.120-.233$ & $\mathrm{CI}=.347-.453$ \\
\hline \multirow{2}{*}{$\begin{array}{l}\text { HEXACO Agreea- } \\
\text { bleness }\end{array}$} & $r=-.123 * * *$ & $r=-.220 * * *$ & $r=.209 * * *$ & $r=.164 * * *$ & $r=-.118 * * *$ & $r=.007$ \\
\hline & $\mathrm{CI}=-.176-.063$ & $C I=-.272--.164$ & $\mathrm{CI}=.157-.260$ & $\mathrm{CI}=.116-.215$ & $\mathrm{CI}=-.175-.063$ & $\mathrm{CI}=-.053-.064$ \\
\hline \multirow{2}{*}{$\begin{array}{l}\text { HEXACO Conscien- } \\
\text { tiousness }\end{array}$} & $r=-.061^{*}$ & $r=-.321 * * *$ & $r=-.018$ & $r=.196 * * *$ & $r=-.211 * * *$ & $r=-.085^{* * *}$ \\
\hline & $\mathrm{CI}=-.110-.009$ & $\mathrm{CI}=-.369-.164$ & $\mathrm{CI}=-.074-.033$ & $\mathrm{CI}=.149-.245$ & $\mathrm{CI}=-.263-.153$ & $\mathrm{CI}=-.136-.034$ \\
\hline \multirow{2}{*}{$\begin{array}{l}\text { HEXACO Openness } \\
\text { to experience }\end{array}$} & $r=-.061^{*}$ & $r=.101 * * *$ & $r=-.028$ & $r=.047$ & $r=.136^{* * *}$ & $r=-.110 * * *$ \\
\hline & $\mathrm{CI}=-.110-.009$ & $\mathrm{CI}=.052-.152$ & $\mathrm{CI}=-.084-.026$ & $\mathrm{CI}=-.007-.103$ & $\mathrm{CI}=.075-.192$ & $\mathrm{CI}=-.164-.056$ \\
\hline
\end{tabular}

CI refers to $95 \%$ confidence interval

${ }^{*} P<.05 ; * * P<.01 ; * * * P<.001$ 
RMSEA $=0.08$. The items demonstrated good factor loadings (see Table 3).

\section{Latent Profile Analysis (LPA)}

LPA was conducted to identify the optimal number of classes, models with two to six classes were estimated. The BIC statistic decreased with each model. The Entropy statistic decreased from class two to class three, increased from class three to class four, and decreased from class four to class five and six. The LMR was non-significant for all models except for the four-class model. Also, the $\mathrm{N}$ per class was not higher than the used parameters in the six class model. Hence, the four-class model was favored based on the LMR, Entropy, and $\mathrm{N}$ within classes $>\mathrm{N}$ parameters (See Table 4).

To analyze whether the four different classes differed in their pattern of social reward value, a 6 (social reward value: admiration, negative social potency, passivity, prosocial interactions, sexual relationships, sociability) $\times 4$ (class: 1 , $2,3,4)$ repeated-measures ANOVA was conducted. Due to violation of sphericity, Greenhouse-Geisser correction was used. Bonferroni correction was used to control for multiple comparisons. Significant main effects of social reward and class and a significant social reward $\times$ class interaction were found, $F(3.800,7175.45)=759.046, p<0.001$, eta ${ }^{2}=0.287 ; F(3,1888)=661.261, p<0.001$, eta ${ }^{2}=0.512$; and $F(11.401,7175.45)=162.150, p<0.001, e t a^{2}=0.205$, respectively (See Fig. 1). Subsequently, pair-wise comparisons indicated that, overall, the levels of the subscales of the SRQ differed from each other (all $p$ 's $<0.001$ ). Only Admiration and Sociability did not significantly differ from each other $(p=1.000)$. Group-wise comparisons revealed that, all classes differed significantly from one another regarding the SRQ subscales (all $p$ 's $<0.001$ ). Only class 1 and 3 did not significantly differ $(p=1.000)$. Finally, the classes differed in their pattern of social reward value in the way that class one and four displayed low levels on Negative Social Potency, whereas class two and three displayed higher levels. Also, class one, two, and four displayed high levels on Prosocial Interactions, whereas class three displayed low levels.

To analyze whether age and gender functioned as confounding variables, the analysis described above was conducted again, now with age as a covariate and gender as an additional between-subjects factor. Results showed that age and gender were not associated with social reward valuation when included as covariates, $F(1,1850)=0.49, p=0.485$, eta ${ }^{2}=0.000$; and $F(1,1850)=0.12, p=0.731$, eta $^{2}=0.000$, respectively. Therefore, in subsequent analyses age and gender were not included as covariates.

Subsequently, a MANOVA was conducted to investigate whether the four classes could be further typified by psychopathy, aggression, social anxiety, and personality characteristics. A significant multivariate effect of group was found, Wilks' Lambda $=0.590, F(45,3898.398)=14.763$, $p<0.001, \eta_{p}{ }^{2}=0.144$. Separate univariate ANOVAs showed significant group differences for the SRP interpersonal, affective, lifestyle, antisocial and total score, LSAS anxiety and avoidance score, proactive and reactive aggression (RPQ), and the subscales honesty-humility, emotion, extraversion, agreeableness, conscientiousness, and openness to experience of the HEXACO (See Table 5). ${ }^{1}$ These results showed that Class one $(\mathrm{N}=431,22.78 \%)$ was characterized by low scores on psychopathy and aggression, low to moderate social anxiety, and high honesty-humility, emotion, agreeableness, and conscientiousness, moderate extraversion, and low openness to experience. Class two $(\mathrm{N}=154$, $8.14 \%$ ) was characterized by high levels of psychopathic traits (interpersonal, affective, and lifestyle), high reactive aggression, moderate proactive aggression, moderate to high social anxiety, and low honesty-humility, emotion, agreeableness, and conscientiousness, moderate extraversion, and high openness to experience. Class three $(\mathrm{N}=50,2.64 \%)$ was characterized by high levels of psychopathic traits (interpersonal, affective, lifestyle, antisocial), high social anxiety, high proactive and reactive aggression, and low honesty-humility and conscientiousness, moderate openness to experience, low to moderate emotion and agreeableness, and moderate to high extraversion. Finally, Class four $(\mathrm{N}=1257,66.44 \%)$ was characterized by low levels of social anxiety, moderate psychopathy (interpersonal, affective, lifestyle, but low on antisocial), moderate reactive aggression, and moderate honesty-humility, conscientiousness, and openness to experience, high emotion and extraversion, and low to moderate agreeableness. Figures 2 and 3 visualizes the scores on the external variables for each of the latent Classes.

\section{Discussion}

The current study investigated the validity and reliability of the Dutch version of the SRQ, as well as individual differences in social reward valuation through LPA. The results showed that the descriptive statistics pertaining to the subscales of the Dutch SRQ were consistent with those of the original version (Foulkes et al., 2014b). Confirmatory factor analysis showed that the original six-factor structure was confirmed in the present sample. Only the chi-square value did not indicate a good fit, but this finding is in line with those obtained by Foulkes et al. (2014b) for the original version. It is important to note that the Chi-square statistic is sensitive to sample size and often rejects the model

\footnotetext{
1 The results for the subscales SRP antisocial and RPQ proactive remained significant using non-parametric analyses (p's $<.001$ ). These analyses were conducted to verify the results as the values for skewness and kurtosisfor these subscales were relatively high (Kim, 2013).
} 
Table 3 Factor loadings original six-factor model

\section{Item}

Standardized factor loadings

\section{Admiration}

I enjoy being around people who think I am an important, exciting person

$724 *$

Ik geniet ervan om bij mensen te zijn die denken dat ik een belangrijke, opwindende persoon ben

I enjoy it if others look up to me

$.813 *$

Ik geniet ervan als anderen naar me kijken/me bewonderen

11 I enjoy being around people who are impressed with who I am and what I do

$.801^{*}$

Ik geniet ervan om bij mensen te zijn die onder de indruk zijn van wie ik ben en wat ik doe

18

I enjoy achieving recognition from others

$.617^{*}$

Ik geniet ervan om erkenning van anderen te verkrijgen

Negative social potency

I enjoy making someone angry

Ik geniet ervan om iemand kwaad te maken

$5 \quad$ I enjoy being nice to someone only if I gain something out of it

$I k$ geniet ervan om enkel vriendelijk te zijn tegen iemand wanneer ik er iets uithaal

I enjoy tricking someone out of something

Ik geniet ervan om iemand te bedriegen

I enjoy embarrassing other

$.644 *$

Ik geniet ervan om anderen in verlegenheid te brengen

17 I enjoy seeing others get hurt

Ik geniet ervan om anderen gekwetst te zien

\section{Passivity}

I enjoy letting someone else tell me what to do

Ik geniet ervan als iemand anders mij vertelt wat ik moet doen

I enjoy someone else making decisions for me

Ik geniet ervan als iemand anders beslissingen voor mij neemt

23 I enjoy following someone else's rules

Ik geniet ervan om de regels van anderen op te volgen

Prosocial interactions

I enjoy treating others fairly

Ik geniet ervan om anderen rechtvaardig te behandelen

I enjoy feeling emotionally connected to someone

$I k$ geniet ervan om me emotioneel verbonden te voelen met iemand

Ik geniet ervan om de beloften die ik aan anderen maak, na te komen

I enjoy it if someone accepts me as Iam, no matter what

Ik geniet ervan als iemand me onvoorwaardelijk aanvaardt zoals ik ben

22 I enjoy making someone feel happy

Ik geniet ervan om iemand gelukkig te maken

\section{Sexual relationships}

Ik geniet ervan om erotische relaties te hebben

13 I enjoy having many sexual experiences

Ik geniet ervan om vele seksuele ervaringen te hebben

20 I enjoy having an active sex life

$I k$ geniet ervan om een actief seksleven te hebben

enjoy being a member

Ik geniet ervan om lid te zijn van een groep of club

\section{*}

*

*

$7 *$


Table 4 Fit Indices Latent Profile Analysis (LPA)

\begin{tabular}{lllll}
\hline Classes & BIC & Entropy & LMR $\boldsymbol{p}$-value & N Parameters \\
\hline 2 & $32,797.125$ & .962 & .01 & N per class $>$ N parameters \\
3 & $32,061.676$ & .818 & .06 & N per class $>$ N parameters \\
$4^{*}$ & $31,683.514$ & .826 & .04 & N per class $>$ N parameters \\
5 & $31,560.816$ & .764 & .34 & N per class $>$ N parameters \\
6 & $31,456.586$ & .828 & .24 & N per class $<$ N parameters \\
\hline
\end{tabular}

BIC Bayesian Information Criteria, LMR Lo-Medel-Rubin likelihood ratio test

*Model with the best fit indices when large samples are used (Hooper et al., 2008). The other three fit indices (RMSEA, CFI and TLI) indicated an acceptable model fit and the factor loadings were also sufficiently high. Thus, the present findings indicate that the proposed six-factor structure for the SRQ scales extends to the Dutch version. Also, the patterns of correlations found in the current study are in line with previous research (Foulkes et al., 2014b, 2017). However, no associations were found between social anxiety and SRQ Sociability. It can be reasoned that individuals high in social anxiety experience difficulties in engaging in social interactions. This may be related to evaluating this social engagement as less rewarding, but this might apply to only a subgroup of socially anxious individuals. As the sample mainly consisted of undergraduate students it may be that this subgroup was not well represented. Resulting in no correlations between these measures. However, there was an association between the LSAS and
SRQ passivity. This may reflect the socially withdrawn-like behavior often seen in socially anxious individuals.

The person-based approach revealed four classes of individuals based on social reward valuation. The individuals in Class 1 were characterized by a high enjoyment of having kind, reciprocal relationships, and a moderate enjoyment of being flattered, having frequent sexual experiences, and engaging in group interactions. The individuals in Class 2 were characterized by a high enjoyment of having kind, reciprocal relationships, being flattered, having frequent sexual experiences, and engaging in group interactions, but also by a relatively high enjoyment of being cruel. Thus, individuals in this class seem to enjoy social processes with a high value in general, irrespective of whether these processes have a negative or positive effect on others. Class 3 formed the smallest group and consisted of individuals that valued being flattered, having frequent sexual experiences,

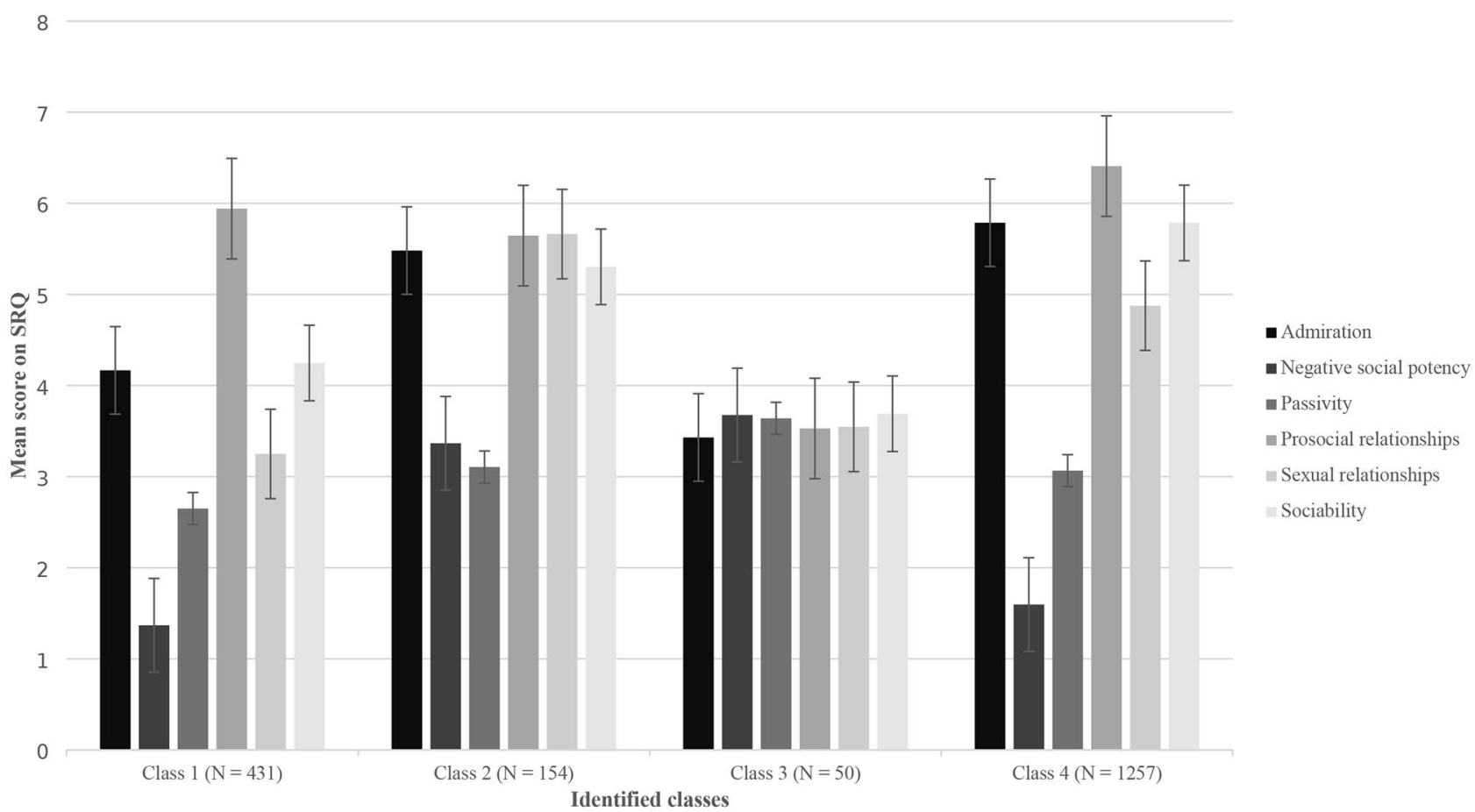

Fig. 1 Mean score on SRQ subscales for each Class 
Table 5 Univariate results, mean scores and standard deviations on questionnaires

\begin{tabular}{|c|c|c|c|c|c|}
\hline Questionnaire & Univariate results & Means Class 1 & Means Class 2 & Means Class 3 & Means Class 4 \\
\hline SRP Interpersonal & $\begin{array}{c}F(3,1326)=65.724 \\
p<.001, \eta p^{2}=.129\end{array}$ & $\begin{array}{l}M=10.09^{\mathrm{a}} \\
\quad(S D=3.47)\end{array}$ & $\begin{array}{l}M=16.70^{\mathrm{b}} \\
\quad(S D=5.37)\end{array}$ & $\begin{array}{l}M=14.17^{\mathrm{b}} \\
\quad(S D=4.69)\end{array}$ & $M=11.35^{\mathrm{c}}(S D=4.18)$ \\
\hline SRP Affective & $\begin{array}{c}F(3,1326)=68.685 \\
p<.001, \eta p^{2}=.134\end{array}$ & $M=8.09^{\mathrm{a}}(S D=2.62)$ & $\begin{array}{l}M=12.74^{\mathrm{b}} \\
\quad(S D=4.45)\end{array}$ & $\begin{array}{c}M=13.39^{\mathrm{b}} \\
\quad(S D=4.15)\end{array}$ & $M=9.00^{\mathrm{c}}(S D=3.08)$ \\
\hline SRP Lifestyle & $\begin{array}{c}F(3,1326)=70.727 \\
\quad p<.001, \eta p^{2}=.138\end{array}$ & $\begin{array}{c}M=10.84^{\mathrm{a}} \\
\quad(S D=3.52)\end{array}$ & $\begin{array}{l}M=17.58^{\mathrm{b}} \\
\quad(S D=4.80)\end{array}$ & $\begin{array}{c}M=16.22^{\mathrm{b}} \\
\quad(S D=5.12)\end{array}$ & $M=12.89^{\mathrm{c}}(S D=4.21)$ \\
\hline SRP Antisocial & $\begin{array}{c}F(3,1326)=46.934 \\
p<.001, \eta p^{2}=.096\end{array}$ & $M=6.39^{\mathrm{a}}(S D=1.99)$ & $M=8.18^{\mathrm{b}}(S D=3.12)$ & $\begin{array}{l}M=11.09^{\mathrm{c}} \\
\quad(S D=5.81)\end{array}$ & $M=6.59^{\mathrm{a}}(S D=1.99)$ \\
\hline SRP Total & $\begin{array}{c}F(3,1326)=89.757 \\
p<.001, \eta p^{2}=.169\end{array}$ & $\begin{array}{l}M=37.63^{\mathrm{a}} \\
\quad(S D=9.93)\end{array}$ & $\begin{array}{l}M=58.11^{\mathrm{b}} \\
\quad(S D=15.34)\end{array}$ & $\begin{array}{l}M=68.48^{\mathrm{b}} \\
\quad(S D=19.81)\end{array}$ & $\begin{array}{l}M=42.09^{\mathrm{c}} \\
\quad(S D=11.48)\end{array}$ \\
\hline LSAS Anxiety & $\begin{array}{l}F(3,1326)=9.680 \\
\quad p<.001, \eta p^{2}=.021\end{array}$ & $\begin{array}{l}M=42.24^{\mathrm{a}, \mathrm{c}} \\
\quad(S D=16.11)\end{array}$ & $\begin{array}{l}M=44.86^{\mathrm{a}, \mathrm{b}} \\
\quad(S D=15.99)\end{array}$ & $\begin{array}{l}M=53.52^{\mathrm{b}} \\
\quad(S D=17.74)\end{array}$ & $\begin{array}{l}M=40.15^{\mathrm{c}} \\
\quad(S D=13.71)\end{array}$ \\
\hline LSAS Avoidance & $\begin{array}{l}F(3,1326)=10.625 \\
\quad p<.001, \eta p^{2}=.023\end{array}$ & $\begin{array}{l}M=36.82^{\mathrm{a}} \\
\quad(S D=14.62)\end{array}$ & $\begin{array}{l}M=38.19^{\mathrm{a}} \\
\quad(S D=15.44)\end{array}$ & $\begin{array}{l}M=46.78^{\mathrm{b}} \\
\quad(S D=18.73)\end{array}$ & $\begin{array}{l}M=34.46^{\mathrm{c}} \\
\quad(S D=11.44)\end{array}$ \\
\hline$R P Q$ Proactive & $\begin{array}{l}F(3,1326)=83.327 \\
p<.001, \eta p^{2}=.159\end{array}$ & $\begin{array}{l}M=12.73^{\mathrm{a}} \\
\quad(S D=1.45)\end{array}$ & $\begin{array}{l}M=15.40^{\mathrm{b}} \\
\quad(S D=3.68)\end{array}$ & $\begin{array}{l}M=16.96^{c} \\
\quad(S D=6.18)\end{array}$ & $M=12.88^{\mathrm{a}}(S D=1.57)$ \\
\hline$R P Q$ Reactive & $\begin{array}{l}F(3,1326)=14.206 \\
p<.001, \eta p^{2}=.031\end{array}$ & $\begin{array}{c}M=15.49^{\mathrm{a}} \\
\quad(S D=3.48)\end{array}$ & $\begin{array}{l}M=17.97^{\mathrm{b}} \\
\quad(S D=3.91)\end{array}$ & $\begin{array}{c}M=17.78^{\mathrm{b}, \mathrm{c}} \\
\quad(S D=5.06)\end{array}$ & $M=16.48^{\mathrm{c}}(S D=3.47)$ \\
\hline НЕХАСО $\mathrm{HH}$ & $\begin{array}{l}F(3,1326)=42.420 \\
\quad p<.001, \eta p^{2}=.088\end{array}$ & $M=3.58^{\mathrm{a}}(S D=.49)$ & $M=2.96^{\mathrm{b}}(S D=.46)$ & $M=2.91^{\mathrm{b}}(S D=.52)$ & $M=3.39^{\mathrm{c}}(S D=.52)$ \\
\hline HEXACO Emotion & $\begin{array}{l}F(3,1326)=13.698 \\
p<.001, \eta p^{2}=.030\end{array}$ & $M=3.34^{\mathrm{a}}(S D=.67)$ & $M=2.99^{\mathrm{b}}(S D=.62)$ & $M=3.07^{\mathrm{a}, \mathrm{b}}(S D=.54)$ & $M=3.39^{\mathrm{a}}(S D=.62)$ \\
\hline $\begin{array}{l}\text { HEXACO Extraver- } \\
\text { sion }\end{array}$ & $\begin{array}{l}F(3,1326)=24.236 \\
p<.001, \eta p^{2}=.052\end{array}$ & $M=3.18^{\mathrm{a}}(S D=.69)$ & $M=3.30^{\mathrm{a}}(S D=.62)$ & $M=3.26^{\mathrm{a}, \mathrm{b}}(S D=.38)$ & $M=3.51^{\mathrm{b}}(S D=.57)$ \\
\hline $\begin{array}{l}\text { HEXACO Agreeable- } \\
\text { ness }\end{array}$ & $\begin{array}{l}F(3,1326)=10.096 \\
p<.001, \eta p^{2}=.022\end{array}$ & $M=3.30^{\mathrm{a}}(S D=.59)$ & $M=2.97^{\mathrm{b}}(S D=.55)$ & $M=2.97^{\mathrm{b}, \mathrm{c}}(S D=.40)$ & $M=3.23^{\mathrm{a}, \mathrm{c}}(S D=.55)$ \\
\hline HEXACO Conscien & $\begin{array}{c}F(3,1326)=22.814 \\
p<.001, \eta p^{2}=.049\end{array}$ & $M=3.73^{\mathrm{a}}(S D=.59)$ & $M=3.17^{\mathrm{b}}(S D=.69)$ & $M=3.19^{\mathrm{b}}(S D=.39)$ & $M=3.58^{\mathrm{c}}(S D=.63)$ \\
\hline $\begin{array}{l}\text { HEXACO Openness to } \\
\text { experience }\end{array}$ & $\begin{array}{l}F(3,1326)=2.698 \\
\quad p=.045, \eta p^{2}=.006\end{array}$ & $M=3.07^{\mathrm{a}}(S D=.69)$ & $M=3.29^{\mathrm{b}}(S D=.64)$ & $M=3.12^{\mathrm{a}, \mathrm{b}}(S D=.46)$ & $M=3.16^{\mathrm{a}, \mathrm{b}}(S D=.71)$ \\
\hline
\end{tabular}

Superscripts of mean values indicate significant group differences: Groups with different superscripts differ from each other at least $p<.05$

and engaging in group interactions moderately as socially rewarding and were further characterized by a relatively high enjoyment of being cruel. Finally, the individuals in Class 4 formed the largest group and were characterized by a high enjoyment of having kind, reciprocal relationships, being flattered, having frequent sexual experiences, and engaging in group interactions. Based on these different patterns we labelled Class 1 as Low Social Interest, Class 2 as Undifferentiated Social Reward-seekers, Class 3 as Socially Cruel, and Class 4 as the High Social Interest class.

The large High Social Interest class (Class 4) was characterized by low scores on psychopathy, aggression, social anxiety, and higher scores on extraversion. The large number of individuals included in this group indicates that this is the pattern of social behavior and reward valuation that can be seen in most individuals. Therefore, the pattern of SRQ scores displayed by the High Social Interest class are likely to reflect the baseline pattern in the population. The Low Social Interested individuals (Class 1) were typified by somewhat lower scores on the social reward domains in combination with higher levels of social anxiety and moderate scores on extraversion, psychopathy, and aggression. The results suggest that these individuals may still engage in social activities and enjoy these, but that they could be less socially outgoing. Also, it may be speculated that an overall higher/lower social reward valuation differentiates these two classes. Future research has to elucidate whether these general low/high rating also explain the differences in social and anti-social behavior. The Undifferentiated Social Reward-seekers and the Socially Cruel classes (Classes 2 and 3 ) displayed inverted patterns of social reward valuation relative to the other groups. That is, they reported a relatively high enjoyment of being cruel. An inverted pattern of social reward value has previously been found in individuals high in psychopathic traits (Foulkes et al., 2014a, b, 2017).

Indeed, further examination of the differences between the classes revealed that the Undifferentiated Social Rewardseekers and the Socially Cruel class displayed the highest levels of psychopathic traits. The Undifferentiated Social Reward-seekers were characterized by high interpersonal 
Fig. 2 External correlates of the latent profiles. Mean z-scores of each latent Class on a psychopathy (SRP interpersonal, affective, lifestyle, antisocial), aggression subtype (RPQ reactive, proactive), and social anxiety (LSAS avoidance, anxiety)

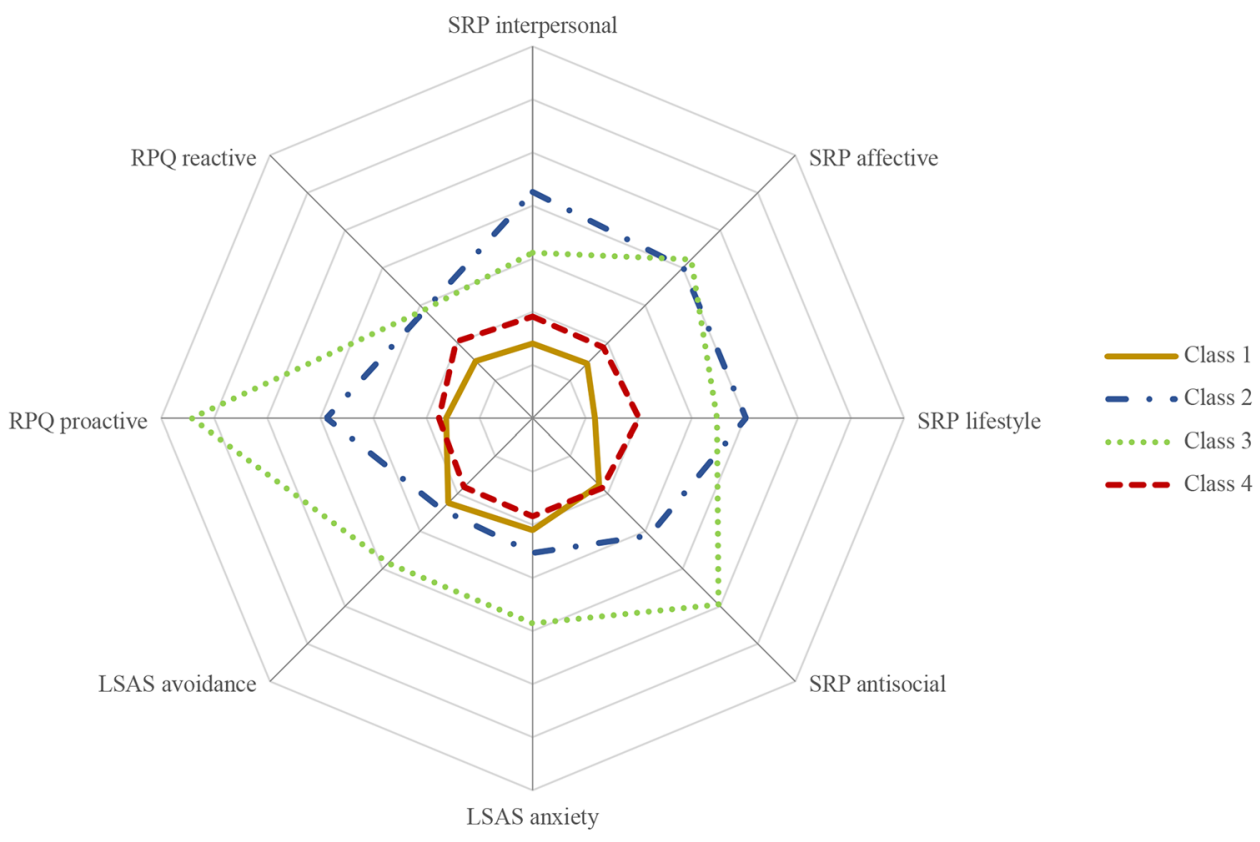

manipulation, callous affect, and erratic life styles, whereas the Socially Cruel group additionally reported a relatively strong tendency to engage in antisocial behavior. Previously, it has been speculated that receiving social approval (SRQ Admiration) is useful in the context of interpersonal manipulation (Foulkes et al., 2014a). This may also account for the other social domains; investing in social interactions/relationships may particular be beneficial for the manipulative treatment of others. Some of these interpersonal contacts may also be used to flatter their own egos. This would suggest that, for individuals high in psychopathic traits, interpersonal kindness and closeness are rewarding because of its utility rather than due to its enjoyableness. This could help explain why the interpersonal facet of psychopathy is often associated with proactive aggression (e.g., Fite et al., 2010). Proactive aggression is defined as deliberate behavior which is often driven by the obtainment of a personal goal or personal gain (Dodge \& Coie, 1987). However, the current results showed that not the Undifferentiated Social Reward-seeking individuals, but those in the Socially Cruel class reported the highest levels of proactive aggression. Strikingly, even though the current sample is a convenience sample, the high level of proactive aggression reported by the Socially Cruel group was comparable to the average
Fig. 3 External correlates of the latent profiles. Mean z-scores of each latent Class on the HEXACO

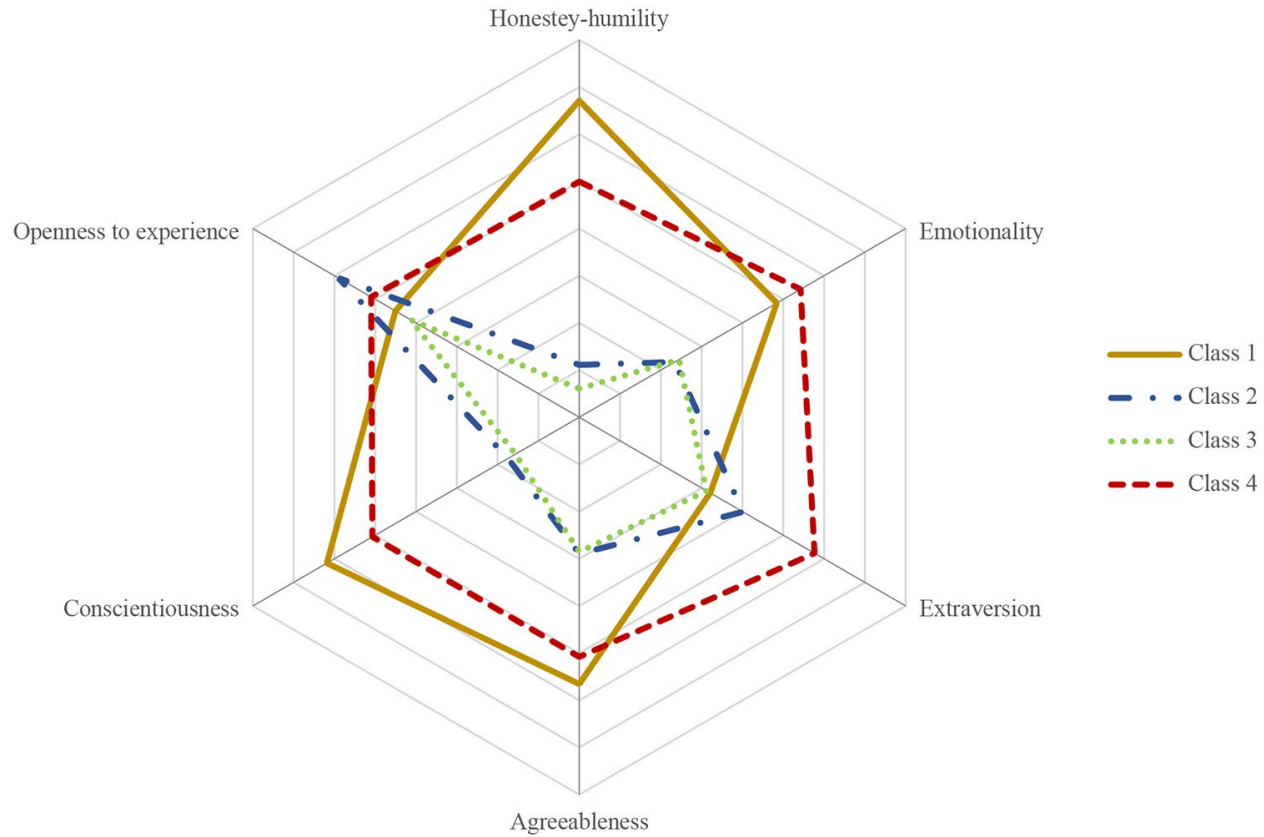


levels seen in forensic populations (e.g., Brugman et al., 2016; Smeijers et al., 2018). The Socially Cruel individuals were further characterized by the highest levels of antisocial tendencies and social anxiety, and the lowest reward value of prosocial interactions. The combination of psychopathy and (social) anxiety might seem paradoxical, but has also been found in previous research (e.g., Gillespie et al., 2015).

Having a high level of anxiety is thought to be characteristic of so-called secondary psychopathy, while primary psychopathy is typified by a lack of anxiety (e.g., Cleckley, 1941; Gillespie et al., 2015; Skeem et al., 2007). It is conceivable that due to social anxiety, interactions with other people will be experienced as less rewarding. This pattern was also found for the Low Social Interest group, but these individuals did not report elevated levels of reactive or proactive aggression. It may be speculated that the combination of higher levels of social anxiety, low social reward values of interpersonal kindness and closeness, high psychopathic traits, including high antisocial tendency, increase the risk of acting out in social deviant behaviors, such as proactive aggression. The items of the RPQ measuring proactive aggression refer to deliberate use of aggressive behavior which is relatively easy to observe (e.g., "Used physical force to get others to do what you want", "Used force to obtain money or things from others", "Threatened and bullied someone"). One notable result is that the Undifferentiated Social Reward-seekers group seems to be relatively indifferent towards the valence of social rewards, because they derive pleasure from hurting others and also find interpersonal kindness and closeness rewarding. One hypothesis is that they may engage more in less observable instrumental behaviors (not represented in the RPQ), such as interpersonal manipulation.

Also, it might be suggested that some antisocial tendencies need to be present in order to in engage in proactive aggressive behavior. The only group characterized by both antisocial tendencies and proactive aggression was the Socially Cruel group. Apart from enjoying being callous, cruel, and using others for personal gains, aggressive behavior itself may be perceived as pleasurable (Blair, 2005; Bushman et al., 2001; Chester \& DeWall, 2015; Ramírez et al., 2005). For instance, aggression can be used because it is expected to alleviate aversive mood states (Bushman et al., 2001), and also because retaliation can be experienced to be hedonically rewarding (Chester \& DeWall, 2015). The likelihood of engaging in aggressive acts could increase when aggressive behavior by itself is experienced as rewarding and enjoyable. When less pleasure is derived from interpersonal kindness and closeness, aggression might even be more accessible as its rewarding function may prevail and will be inhibited less by socialization.

One potential limitation of the current study is that the sample consisted primarily of female participants and, therefore, the results may not be generalizable to men. This is an important consideration to keep in mind given that the prevalence of psychopathy and aggressive behavior is higher among men and gender difference exist in the expression of aggression (e.g., Denson et al., 2018; Gordts et al., 2015). Future research should be conducted to elucidate potential gender differences in a more balanced sample. Also, the current sample consisted of a convenience sample from the general population not primarily typified by elevated levels of aggressive behavior. Only the Socially Cruel class displayed aggression levels comparable to forensic psychiatric population. However, this class represented the smallest group of individuals. Future research needs to replicate the current findings in larger clinical and forensic populations. Also, the HEXACO honesty-humility exhibited questionable reliability. Consequently, the findings regarding this specific subscale have to be interpreted with care. Finally, the present study found a subgroup of individuals high in social anxiety, aggression, and psychopathy. However, our study design did not allow us to investigate the underlying mechanisms that may connect these psychopathologies and that might play an important role in understanding their etiology. Empathy, for instance, may be such an underlying factor. Psychopathic individuals are thought to be characterized by reduced affective empathy but intact cognitive empathy (e.g., Blair, 2013). The same pattern has been observed among socially anxious individuals (Morrison et al., 2016). Future experimental research is needed to elucidate possible interconnecting factors to enhance our understanding of the etiology of these psychopathologies.

Notwithstanding the limitations, the results showed that individuals can be distinguished based on their social reward value pattern. These individual differences in social reward value contribute to our understanding of the underlying motivation of social (deviant) behaviors. More research is needed to reveal how the valuation of social events are associated with different types of psychopathology, and whether this could also provide important new leads for treatment.

\section{Declarations}

Ethical Approval The current study was approved by the institutional review board (ECSW2017-2306-520); the studies conducted in Flanders followed the ethical guidelines of the Thomas More University College.

Consent to Participate Informed consent was obtained from all individual participants included in the study.

Conflict of Interest Danique Smeijers, Kasia Uzieblo, Jeffrey C. Glennon, Josi M.A. Driessen and Inti A. Brazil state that there is no conflict of interest. 
Open Access This article is licensed under a Creative Commons Attribution 4.0 International License, which permits use, sharing, adaptation, distribution and reproduction in any medium or format, as long as you give appropriate credit to the original author(s) and the source, provide a link to the Creative Commons licence, and indicate if changes were made. The images or other third party material in this article are included in the article's Creative Commons licence, unless indicated otherwise in a credit line to the material. If material is not included in the article's Creative Commons licence and your intended use is not permitted by statutory regulation or exceeds the permitted use, you will need to obtain permission directly from the copyright holder. To view a copy of this licence, visit http://creativecommons.org/licenses/by/4.0/.

\section{References}

Arab Mohebi Shahrabi, A., Sadatian, S. M., \& Madani, F. S. (2017). A Study on Factor Structure and Validation of Social Reward Questionnaire in Iranian Youth. International Journal of Behavioral Sciences, 11(3), 96-100. http://www.behavsci.ir/article_67980.html

Ashton, M. C., \& Lee, K. (2009). The HEXACO-60: A short measure of the major dimensions of personality. Journal of Personality Assessment, 91(4), 340-345. https://doi.org/10.1080/00223890902935878

Association, A. P. (2013). Diagnostic and statistical manual of mental disorders (DSM-5). American Psychiatric Association.

Bhanji, J. P., \& Delgado, M. R. (2014). The social brain and reward: social information processing in the human striatum. Wiley Interdisciplinary Reviews: Cognitive Science, 5(1), 61-73. https://doi. org/10.1002/wcs. 1266

Blair, R. J. R. (2005). Applying a cognitive neuroscience perspective to the disorder of psychopathy. Development and Psychopathology, 17(3), 865-891. https://doi.org/10.1017/S0954579405050418

Blair, R. J. R. (2013). The neurobiology of psychopathic traits in youths. Nature Reviews Neuroscience, 14(11), 786-799. https:// doi.org/10.1038/nrn3577

Brugman, S., Cornet, L. J., Smeijers, D., Smeets, K., Oostermeijer, S., Buitelaar, J. K., Verkes, R. J., Lobbestael, J., de Kogel, C. H., \& Jansen, L. (2016). Examining the reactive proactive questionnaire in adults in forensic and non-forensic settings: A variable-and person-based approach. Aggressive Behavior. https://doi.org/10. 1002/ab. 21671

Bushman, B. J., Baumeister, R. F., \& Phillips, C. M. (2001). Do people aggress to improve their mood? Catharsis beliefs, affect regulation opportunity, and aggressive responding. Journal of Personality and Social Psychology, 81(1), 17. https://doi.org/10.1037/0022-3514. 81.1.17

Buss, A. H. (1983). Social rewards and personality. Journal of Personality and Social Psychology, 44(3), 553-563. https://doi.org/10. 1037/0022-3514.44.3.553

Chen, N. T., \& Clarke, P. J. (2017). Gaze-based assessments of vigilance and avoidance in social anxiety: a review. Current Psychiatry Reports, 19(9), 59. https://doi.org/10.1007/s11920-017-0808-4

Chester, D. S., \& DeWall, C. N. (2015). The pleasure of revenge: retaliatory aggression arises from a neural imbalance toward reward. Social Cognitive and Affective Neuroscience, 11(7), 1173-1182. https://doi.org/10.1093/scan/nsv082

Cima, M., Raine, A., Meesters, C., \& Popma, A. (2013). Validation of the Dutch Reactive Proactive Questionnaire (RPQ): Differential correlates of reactive and proactive aggression from childhood to adulthood. Aggressive Behavior, 39(2), 99-113. https:// doi.org/10.1002/ab.21458

Cleckley, H. (1941). The mask of sanity; an attempt to reinterpret the so-called psychopathic personality. Mosby.
Cremers, H. R., Veer, I. M., Spinhoven, P., Rombouts, S. A., \& Roelofs, K. (2015). Neural sensitivity to social reward and punishment anticipation in social anxiety disorder. Frontiers in Behavioral Neuroscience, 8, 439. https://doi.org/10.3389/fnbeh.2014.00439

De Vries, R. E., Ashton, M. C., \& Lee, K. (2009). De zes belangrijkste persoonlijkheidsdimensies en de HEXACO Persoonlijkheidsvragenlijst. Gedrag en Organisatie, 22, 232-274. https://psycnet.apa. org/record/2009-18078-004

Denson, T. F., O’Dean, S. M., Blake, K. R., \& Beames, J. R. (2018). Aggression in women: behavior, brain and hormones. Frontiers in Behavioral Neuroscience, 12, 81. https://doi.org/10.3389/fnbeh. 2018.00081

Dodge, K. A., \& Coie, J. D. (1987). Social-information-processing factors in reactive and proactive aggression in children's peer groups. Journal of Personality and Social Psychology, 53(6), 1146. https://psycnet.apa.org/buy/1988-09195-001

Field, A. (2013). Discovering statistics using IBM SPSS statistics. Sage publications ltd.

Fite, P. J., Raine, A., Stouthamer-Loeber, M., Loeber, R., \& Pardini, D. A. (2010). Reactive and proactive aggression in adolescent males: Examining differential outcomes 10 years later in early adulthood. Criminal Justice Behavior, 37(2), 141-157. https:// doi.org/10.1177/0093854809353051

Foa, E. B., \& Foa, U. G. (1980). Resource theory: Interpersonal behavior as exchange. In K. J. Gergen, M. S. Greenberg, \& R. H. Willis (Eds.), Social exchange: Advances in theory and research (pp. 77-101). Plenum Press.

Foulkes, L., McCrory, E. J., Neumann, C. S., \& Viding, E. (2014a). Inverted social reward: Associations between psychopathic traits and self-report and experimental measures of social reward. PLoS One, 9(8), e106000. https://doi.org/10.1371/journal.pone.0106000

Foulkes, L., Neumann, C. S., Roberts, R., McCrory, E., \& Viding, E. (2017). Social Reward Questionnaire-Adolescent Version and its association with callous-unemotional traits. Royal Society Open Science, 4(4), 160991. https://doi.org/10.1098/rsos.160991

Foulkes, L., Viding, E., McCrory, E. J., \& Neumann, C. S. (2014b). Social Reward Questionnaire (SRQ): development and validation. Frontiers in Psychology, 5, 201. https://doi.org/10.3389/fpsyg. 2014.00201

Gao, Y., Mendez, K., Li, X., \& Wang, M. C. (2018). Autonomic conditioning to monetary and social stimuli and aggression in children. Aggressive Behavior, 44(2), 147-155. https://doi.org/10.1002/ab.21738

Gillespie, S. M., Mitchell, I. J., Satherley, R. -M., Beech, A. R., \& Rotshtein, P. (2015). Relations of distinct psychopathic personality traits with anxiety and fear: Findings from offenders and nonoffenders. PLoS One, 10(11), e0143120. https://doi.org/10.1371/ journal.pone. 0143120

Gliem, J. A., \& Gliem, R. R. (2003). Calculating, interpreting, and reporting Cronbach's alpha reliability coefficient for Likert-type scales. Midwest Research-to-Practice Conference in Adult, Continuing, and Community Education.

Gordts, S., Uzieblo, K., Neumann, C., Van den Bussche, E., \& Rossi, G. (2015). Validity of the Self-Report Psychopathy Scales (SRPIII full and short versions) in a community sample. Assessment, 24(3), 308-325. https://doi.org/10.1177/1073191115606205

Hare, R. D. (2003). Manual for the revised psychopathy checklist, 2nd $E d n$. Multi-Health Systems.

Hare, R. D., \& Neumann, C. S. (2008). Psychopathy as a clinical and empirical construct. Annual Review of Clinical Psychology, 4, 217-246. https://doi.org/10.1146/annurev.clinpsy.3.022806.091452

Hesterberg, T., Monaghan, S., Moore, D., Clipson, A., \& Epstein, R. (2003). Bootstrap methods and permutation tests: Companion chapter 18. In The practice of business statistics. W.H. Freemand and Co.

Hooper, D., Coughlan, J., \& Mullen, M. (2008). Structural equation modelling: Guidelines for determining model fit. Electronic 
Journal of Business Research Methods, 6(1), 53-60. https://doi. org/10.1037/1082-989X.12.1.58

Hoyle, R. H. (1995). Structural equation modeling: Concepts, issues, and applications. Sage.

Hu, L. T., \& Bentler, P. M. (1999). Cutoff criteria for fit indexes in covariance structure analysis: Conventional criteria versus new alternatives. Structural Equation Modeling: A Multidisciplinary Journal, 6(1), 1-55. https://doi.org/10.1080/10705519909540118

Kim, H. Y. (2013). Statistical notes for clinical researchers: Assessing normal distribution (2) using skewness and kurtosis. Restorative Dentistry \& Endodontics, 38(1), 52-54. https://doi.org/10.5395/ rde.2013.38.1.52

Li, C. -H. (2016). Confirmatory factor analysis with ordinal data: Comparing robust maximum likelihood and diagonally weighted least squares. Behavior Research Methods, 48(3), 936-949. https://doi. org/10.3758/s13428-015-0619-7

Liebowitz, M. R. (1987). Social phobia. Modern Problems in Pharmacopsychiatry, 22, 141-173. https://doi.org/10.1159/000414022

Ling, S., \& Raine, A. (2018). The neuroscience of psychopathy and forensic implications. Psychology, Crime \& Law, 24(3), 296-312. https://doi.org/10.1080/1068316X.2017.1419243

Morrison, A. S., Mateen, M. A., Brozovich, F. A., Zaki, J., Goldin, P. R., Heimberg, R. G., \& Gross, J. J. (2016). Empathy for positive and negative emotions in social anxiety disorder. Behavior Research and Therapy, 87, 232-242. https://doi.org/10.1016/j.brat. 2016.10.005

Muthén, L. K., \& Muthén, B. O. (1998). Mplus User's Guide (7th ed.). Muthén \& Muthén.

Nylund, K. L., Asparouhov, T., \& Muthén, B. O. (2007). Deciding on the number of classes in latent class analysis and growth mixture modeling: A Monte Carlo simulation study. Structural Equation Modeling: A Multidisciplinary Journal, 14(4), 535-569. https:// doi.org/10.1080/10705510701575396

Paulhus, D., Neumann, C., \& Hare, R. (2010). Manual for the selfreport psychopathy scale. Multi-health systems.

Paulhus, D., Neumann, C., \& Hare, R. (2015). Manual for the SelfReport Psychopathy scale 4th edition. Multi-Health Systems.
Piedmont, R. L. (2014). Inter-item Correlations. In: A. C. Michalos (Eds.), Encyclopedia of Quality of Life and Well-Being Research. Springer.

Raine, A., Dodge, K., Loeber, R., Gatzke-Kopp, L., Lynam, D., Reynolds, C., Stouthamer-Loeber, M., \& Liu, J. H. (2006). The reactive-proactive aggression questionnaire: Differential correlates of reactive and proactive aggression in adolescent boys [Article]. Aggressive Behavior, 32(2), 159-171. https://doi.org/10.1002/ab.20115

Ramírez, J. M., Bonniot-Cabanac, M. -C., \& Cabanac, M. (2005). Can aggression provide pleasure? European Psychologist, 10(2), 136-145. https://doi.org/10.1027/1016-9040.10.2.136

Sideridis, G. D., \& Simos, P. (2010). What is the actual correlation between expressive and receptive measures of vocabulary? Approximating the sampling distribution of the correlation coefficient using the bootstrapping method. International Journal of Educational and Psychological Assessment, 5, 117-133. https:// doi.org/10.1044/1058-0360(2009/08-0035

Skeem, J., Johansson, P., Andershed, H., Kerr, M., \& Louden, J. E. (2007). Two subtypes of psychopathic violent offenders that parallel primary and secondary variants. Journal of Abnormal Psychology, 116(2), 395. https://doi.org/10.1037/0021-843X.116.2.395

Smeijers, D., Brugman, S., von Borries, K., Verkes, R. J., \& Bulten, E. (2018). Lack of correspondence between the reactive proactive questionnaire and the impulsive premeditated aggression scale among forensic psychiatric outpatients. Aggressive Behavior. https://doi.org/10.1002/ab.21767

Van Balkom, A., De Beurs, E., Hovens, J., \& Van Vliet, I. (2004). Meetinstrumenten bij angststoornissen. Tijdschrift voor Psychiatrie, 46(10), 687-692. https://www.tijdschriftvoorpsychiatrie.nl/assets/ articles/articles_1291pdf.pdf

Publisher's Note Springer Nature remains neutral with regard to jurisdictional claims in published maps and institutional affiliations. 